\title{
Facile route for the regioselective synthesis of 1,4-disubstituted 1,2,3-triazole using copper nanoparticles supported on nanocellulose as recyclable heterogeneous catalyst
}

\author{
MITALI CHETIA ${ }^{\mathrm{a}}$, ABDUL A ALI ${ }^{\mathrm{a}}$, ANKUR BORDOLOI ${ }^{\mathrm{b}, *}$ and DIGANTA SARMA ${ }^{\mathrm{a}, *}$ \\ ${ }^{a}$ Department of Chemistry, Dibrugarh University, Dibrugarh, Assam 786 004, India \\ ${ }^{b}$ Nano Catalysis, Catalytic Conversion and Process Division, CSIR - Indian Institute of Petroleum, Mohkampur, \\ Dehradun, Uttarakhand 248 005, India \\ E-mail: dsarma22@gmail.com
}

MS received 30 March 2017; revised 19 May 2017; accepted 21 May 2017

\begin{abstract}
In this work, a green and efficient methodology has been developed for the synthesis of 1,2,3-triazoles by 'copper nanoparticles supported on nanocellulose (CuNPs/NC)-catalyzed azide-alkyne cycloaddition reaction in glycerol, an environmentally benign solvent, with excellent yields. The present catalyst was characterized by TEM, XRD, SEM-EDX and FT-IR spectroscopy. The reusability of the prepared nanocatalyst was examined up to five times without significant loss of catalytic activity.
\end{abstract}

Keywords. Heterogeneous catalysis; cycloaddition; regioselectivity; click reaction; copper nanoparticles.

\section{Introduction}

1,2,3-Triazoles are an important and most useful class of five-membered heterocycles which have plethora of applications starting from industrial fields to pharmaceutical compounds. ${ }^{1-4}$ Many 1,2,3-triazole containing compounds have been found possessing important biological activities such as anti-viral, anti-epileptic, anti-allergic, anti-microbial as well as anti-cancer and anti-HIV activities. ${ }^{5-8}$ The 1,2,3-triazoles are generally formed by the 1,3-dipolar cycloaddition of azides and alkynes which were first introduced by Michael in 1893. Later, it was thoroughly developed by the German Chemist R. Huisgen ${ }^{9}$ and it is the most convenient and straightforward approach for the synthesis of 1,2,3-triazoles. But this classical method produces both the 1,4- and 1,5-regioisomers and the reaction requires elevated temperature. Overcoming these problems, in 2002, Sharpless et al., ${ }^{10}$ and Meldal et al., ${ }^{11}$ independently published their pioneering work on Cu-catalyzed azide-alkyne cycloaddition (CuAAC) reactions, leading to a mild and efficient regioselective synthesis of 1,4disubstituted 1,2,3-triazoles. Considering the important applications of 1,2,3-triazoles, many works have been done on azide-alkyne cycoaddtion for the synthesis of 1,4-disubstituted 1,2,3- triazoles. Most of the CuAAC reactions use homogeneous $\mathrm{Cu}$ (I) source - either by direct addition of a $\mathrm{Cu}(\mathrm{I})$ salt in presence of stabilizing ligands, or by in situ reduction of $\mathrm{Cu}(\mathrm{II})$ by sodium ascorbate or other reducing agents. ${ }^{12}$ However, the complexity of separating the catalyst as well as the requirement for reducing agents and stabilizing ligands cause tricky problems. Therefore, the search for new competent methods offering high yield, mild conditions, recyclability and waste avoidance are highly desirable from an environmental point of view. In this context, heterogeneous catalysis has attracted much attention in developing environmentally benign chemical processes. Moreover, it brings significant advantages, particularly in the removal of the catalyst from the reaction media, which can be done by simple filtration. ${ }^{13}$ In an effort to find heterogeneous copper catalysts, $\mathrm{Cu}(0)$ on charcoal, ${ }^{14} \mathrm{Cu}(0)$ nanoparticles, ${ }^{15}$ or nanoporous $\mathrm{Cu}(0),{ }^{16}$ $\mathrm{CuO}-\mathrm{CeO}_{2}$ nanocomposite, ${ }^{17}$ porous $\mathrm{Cu}^{18}$ as well as microwave irradiated $\mathrm{Cu}$ turnings ${ }^{19}$ have also successfully established activity for $\mathrm{CuAAC}$ reaction.

\footnotetext{
*For correspondence
}

Electronic supplementary material: The online version of this article (doi:10.1007/s12039-017-1318-y) contains supplementary material, which is available to authorized users. 
Cellulose is Earth's most abundant and ubiquitous natural biopolymer and serves as a bio-compatible support for the catalysts. Thus, it is an excellent starting material for developing new, more sustainable materials from renewable resources. ${ }^{20,21}$ Cellulose nanocrystallites are particularly more important and appealing derivative of cellulose as they possess unique properties of high crystalline order, well defined size and morphology, a controlled surface chemistry, and superior mechanical strength. ${ }^{22}$ In recent years, nano-catalysis has come out as a sustainable alternative to conventional catalysis due to unique properties of the metal nanoparticles like a high surface-to-volume ratio, which enhances their activity and selectivity, while at the same time maintaining the intrinsic features of a heterogeneous catalyst. ${ }^{23}$ Cellulose-supported cuprous iodide nanoparticles (Cell-CuI NPs) have been used for one pot synthesis of 1,4-disubstituted 1,2,3-triazoles. ${ }^{24}$ The long and tedious procedures were normally required for the heterogenization of copper and hence, there is still demand to develop easy-to-prepare and versatile heterogeneous copper catalysts that easily facilitate the synthesis of triazoles. Owing to our dedication to study 'click reaction', ${ }^{25-31}$ herein we report a facile synthesis of 1,2,3-triazoles by copper nanoparticles supported on nanocellulose (CuNPs/NC) as a highly efficient and recyclable heterogeneous catalyst in glycerol at room temperature.

\section{Experimental}

\subsection{Materials and methods}

Reagents and solvents were purchased from Spectrochem, Merck and Sigma Aldrich and used without further purification. All reactions were carried out in oven-dried glassware. All reactions were monitored by thin layer chromotography on aluminium sheets pre-coated with silica gel $60 \mathrm{~F}_{254}$ (Merck) and was visualized under $254 \mathrm{~nm}$ UV light. Melting points (M.p.) were obtained on a BÜCHI Melting Point B-540. ${ }^{1} \mathrm{H}$ NMR $(400 \mathrm{MHz}),{ }^{13} \mathrm{C}$ NMR $(100 \mathrm{MHz})$ spectra were measured on a Bruker Avance $400 \mathrm{MHz}$ spectrometer. Chemical shifts are reported in parts per million (ppm,

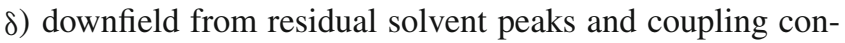
stants are reported as Hertz $(\mathrm{Hz})$. Splitting patterns are designated as singlet (s), doublet (d), triplet (t). Splitting patterns that could not be interpreted is designated as multiplet (m).

\subsection{Catalyst preparation}

The first step in the accomplishment of the goal for the synthesis of CuNPs/NC was the synthesis of nanocellulose

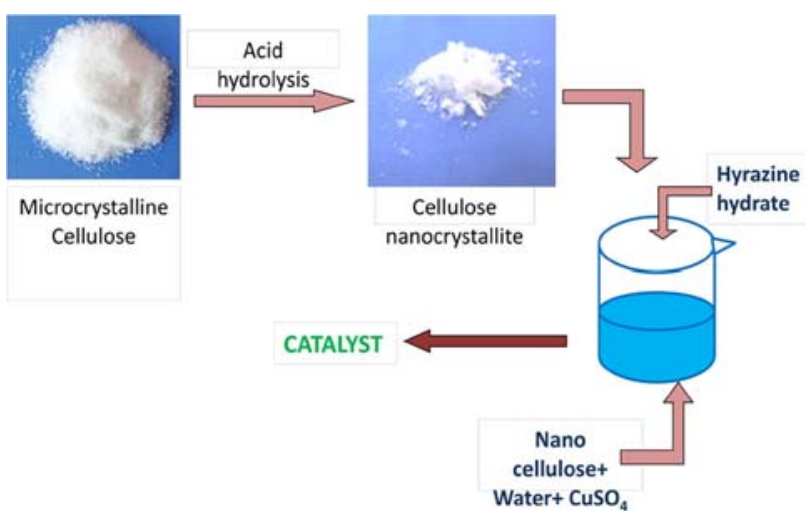

Scheme 1. Preparation of the catalyst.

which is prepared by acid hydrolysis procedure reported elsewhere. Briefly, the microcrystalline cellulose was acid hydrolysed with sulphuric acid concentration of $63 \mathrm{wt} \%$ at $45^{\circ} \mathrm{C}$ for $105 \mathrm{~min}$ to remove the amorphous regions and were neutralized using a series of centrifugation cycles, and thereafter sonicated to individualise the nanocrystals (Scheme 1). ${ }^{32,33}$

To prepare $\mathrm{Cu}$ nanoparticles over nanocellulose, nanocellulose suspension was dispersed with $\mathrm{CuSO}_{4} \cdot 5 \mathrm{H}_{2} \mathrm{O}(0.5$ g) in water $(500 \mathrm{~mL})$ at room temperature for $30 \mathrm{~min}$. Then, hydrazine hydrate $(50 \%, 10 \mathrm{~mL})$ was added drop wise for $30 \mathrm{~min}$ and the reaction mixture was stirred at room temperature for $2 \mathrm{~h}$. The obtained solid was centrifuged and washed with distilled water and acetone, to remove un-reacted reagents. The product was dried at $100^{\circ} \mathrm{C}$ for $10 \mathrm{~h}$ and stored in desiccators. The resultant product was characterized by FT-IR, XRD, SEM-EDX, and TEM analysis.

\subsection{Catalyst characterisation}

The copper nanoparticles supported on nanocellulose (CuNPs/NC) catalyst was fully characterised in order to determine their nature and morphology. The weight percentage of copper was found to be $3.31 \mathrm{wt} \%$ by inductively coupled plasma-atomic emission spectroscopy (ICP-AES) analysis. Transmission electron microscopy (TEM) revealed the presence of well-dispersed nanoparticles with an average size of 6-7 nm (Figure 1). The EDX pattern determined the elemental compositions of different elements in the Cell-Cu sample (Figure 2). The characteristic peaks of $\mathrm{C}, \mathrm{O}$ and $\mathrm{Cu}$ confirmed that the Cell-Cu sample is composed of $\mathrm{C}, \mathrm{O}$ and $\mathrm{Cu}$ elements. The infrared spectrum of catalyst in the range of $500-4000 \mathrm{~cm}^{-1}$ is presented in Figure 3(a). The significant feature in the FT-IR spectrum is the appearance of peak at $806.61 \mathrm{~cm}^{-1}$ for $\mathrm{Cu}-\mathrm{O}$ stretching vibration. Bands of 1050 $1650 \mathrm{~cm}^{-1}$ due to $\mathrm{C}-\mathrm{OH}$ groups and that of $2700-3500 \mathrm{~cm}^{-1}$ due to $\mathrm{O}-\mathrm{H}$ and $\mathrm{C}-\mathrm{H}$ groups were observed concerning to nanocellulose. The XRD pattern shows characteristic peaks of copper(I) nanoparticles, presenting all the phases of $\mathrm{Cu}_{2} \mathrm{O}$ (JCPDS card no -78-2076) as shown in Figure 3(b). 


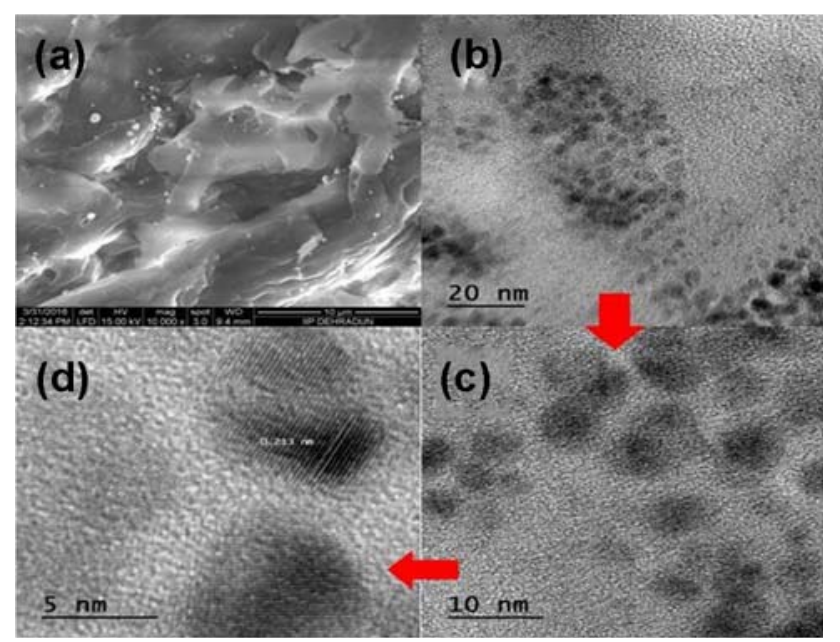

Figure 1. (a) SEM image of the CuNPs/NC, the surface morphology of nanocellulose support is observed to be very smooth. (b), (c) and (d) show the HRTEM images of the prepared catalyst. The HRTEM images evidence the presence of well dispersed nanoparticles in the support. The average particle size is found to be $6-7 \mathrm{~nm}$.

\subsection{General procedure for the synthesis of 1,4-disubstituted-1H-1,2,3-triazole}

To a mixture of azide 1 ( $1 \mathrm{mmol}, 1$ equiv.) and acetylene 2 ( $1.1 \mathrm{mmol}, 1.1$ equiv.) in glycerol $(2 \mathrm{~mL})$ was added the catalyst (20 mg, $3.31 \mathrm{wt} \%, 1.05 \mathrm{~mol} \%$ ). The mixture was stirred at room temperature for an appropriate time. The progress of the reaction was monitored by TLC. After completion of the reaction it was extracted with EtOAc $(2 \times 20 \mathrm{~mL})$, washed with brine, dried over anhydrous sodium sulfate. The solvent was removed under reduced pressure to give the crude product and purified through silica gel column chromatography (10-20\% EtOAc/hexanes) to get the desired product. The products were characterized by ${ }^{1} \mathrm{H}$ and ${ }^{13} \mathrm{C}$ NMR spectroscopy.

\section{Results and Discussion}

The experiments began with the aim of optimizing the reaction conditions for $\mathrm{CuAAC}$ reaction of benzyl
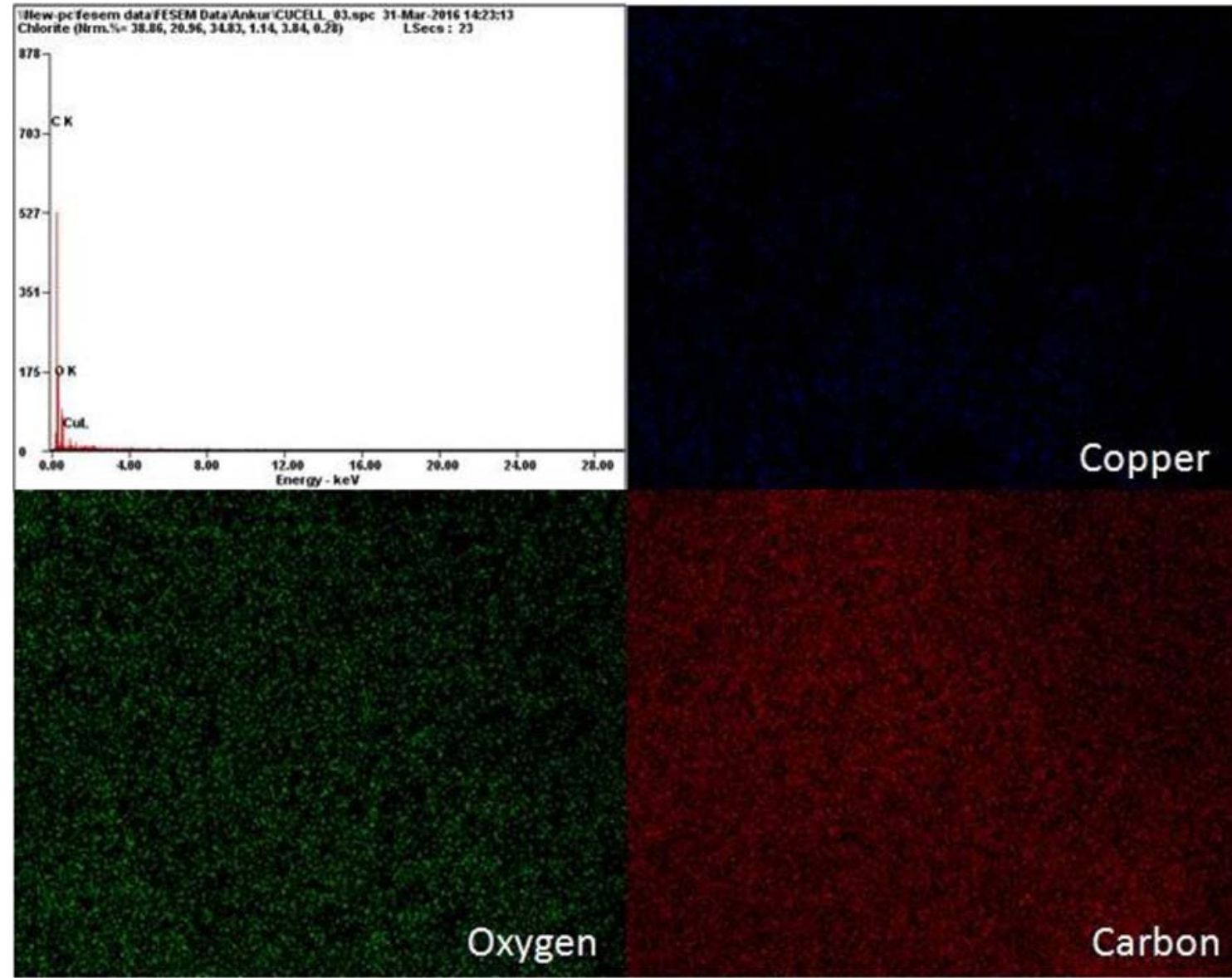

Figure 2. EDX pattern of the catalyst. 

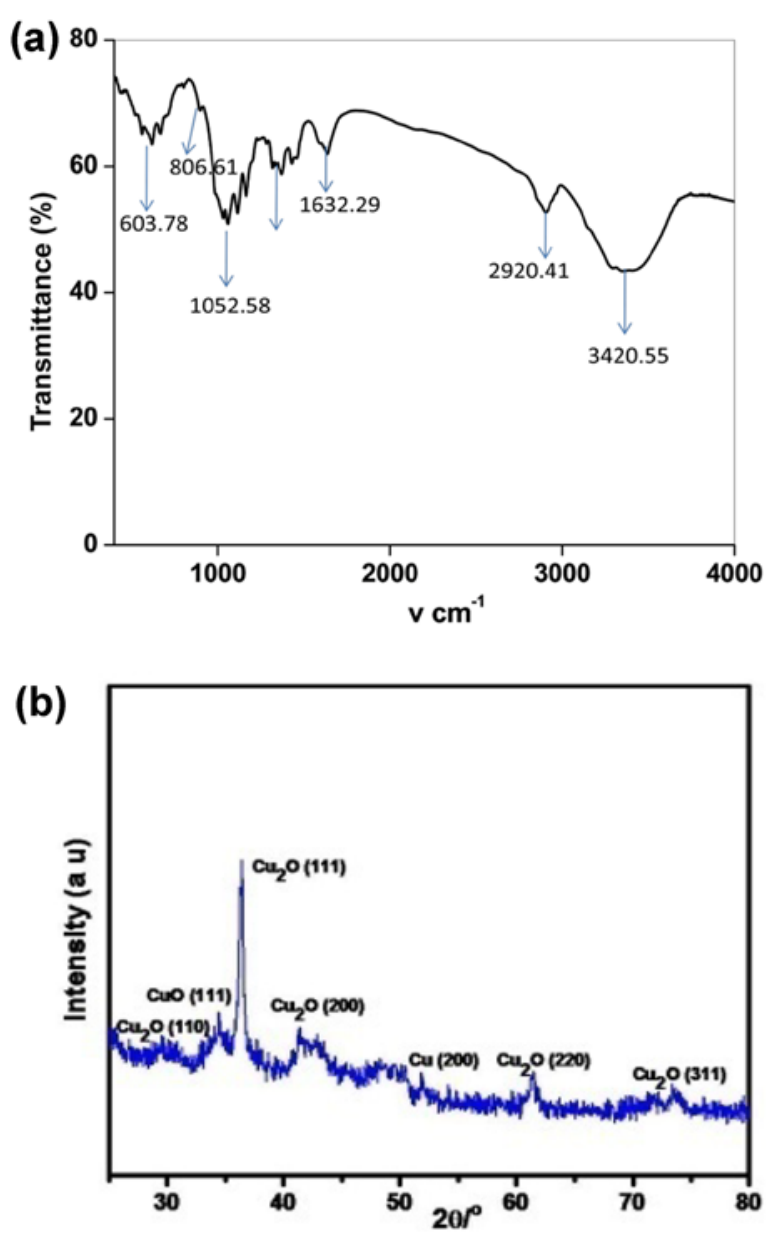

Figure 3. (a) FTIR spectrum and (b) XRD pattern of the catalyst. azide and phenylacetylene. At the first step, the reaction between benzyl azide and phenyl acetylene was allowed to run without solvent, adding $20 \mathrm{mg}$ of the catalyst. But no noticeable progress of the reaction was observed. Then the model reaction was performed with different solvents and among them glycerol was found superior than others (Table 1).

Having identified glycerol as the best solvent for the reaction, we then investigated catalyst loading for the reaction. However, upon lowering the catalyst concentration to $5 \mathrm{mg}$ the reaction still proceeded but afforded only $55 \%$ yield (Table 1 , entry 11 ). Therefore a catalyst loading of $20 \mathrm{mg}$ appeared to be optimal with respect to yield and reaction time (Table 1, entry 7 ).

Taking the optimized reaction conditions in hand, the scope of the cycloaddition reaction using CuNPs/NC was investigated with various alkynes and azides at room temperature. The results are summarized in Table 2 . Both aromatic and aliphatic terminal alkynes readily reacted with the diverse azides to give the corresponding 1,2,3-triazoles in good to excellent yields in most of the tested reactions.

We then examined the possibility of recycling the catalyst. The recyclability of CuNPs/NC was tested in the cycloaddition of phenylacetylene and benzyl azide (Figure 4). After each cycle the catalyst was recovered by simple filtration and reused after washing with ethyl acetate and drying in the air. The activity of the catalyst was found to decrease to a minor extent in the reuse; about $90 \%$ of the original activity was obtained even after the fifth run. Moreover, there was no sig-

Table 1. Solvent optimization study ${ }^{\mathrm{a}}$.

\begin{tabular}{lllc} 
Entry & \multicolumn{1}{c}{ Solvent } & Catalyst loading $(\mathrm{mg})$ & Yield $(\%)^{\mathrm{b}}$ \\
\hline 1 & - & 20 & Trace \\
2 & $\mathrm{H}_{2} \mathrm{O} / \mathrm{t}-\mathrm{BuOH}(1: 1)$ & 20 & 60 \\
3 & $\mathrm{H}_{2} \mathrm{O}$ & 20 & 89 \\
4 & $\mathrm{THF}$ & 20 & 48 \\
5 & $\mathrm{THF} / \mathrm{H}_{2} \mathrm{O}$ & 20 & 60 \\
6 & Acetonitrile & 20 & 65 \\
7 & Glycerol & 20 & 99 \\
8 & DMF & 20 & 40 \\
9 & DMSO & 20 & 65 \\
10 & Glycerol & 10 & 55 \\
11 & Glycerol & 5 & \\
\hline
\end{tabular}

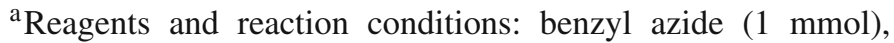
phenyl acetylene $(1.1 \mathrm{mmol})$, catalyst $(20 \mathrm{mg}, 1.05 \mathrm{~mol} \%)$ in the given solvent $(2 \mathrm{~mL})$ was stirred at room temperature for $4 \mathrm{~h}$ in open air. ${ }^{b}$ Isolated yields. 
Table 2. Scope of cycloaddition reaction of different azides and alkynes ${ }^{\mathrm{a}}$.

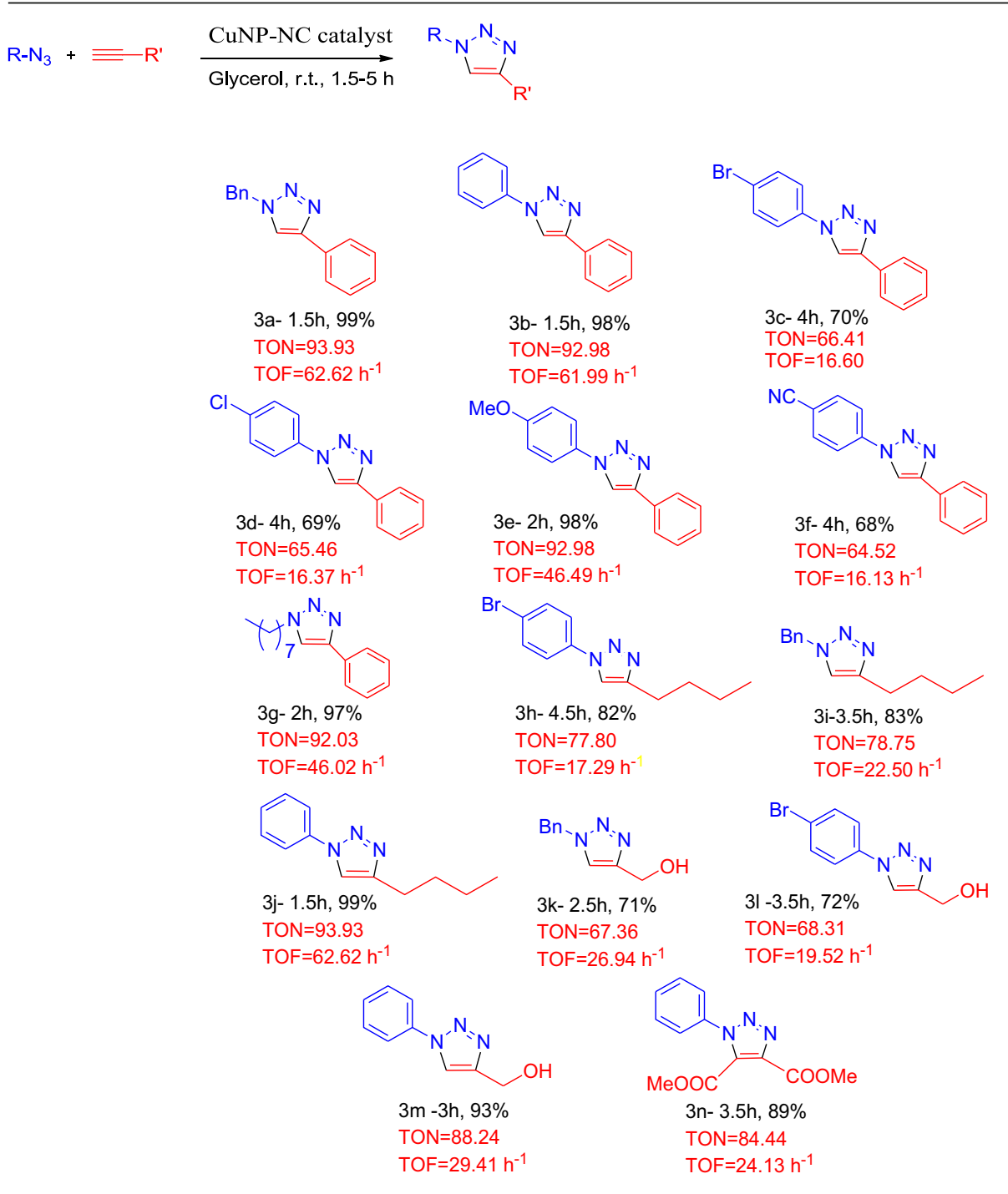

${ }^{a}$ Reagents and reaction conditions: azide $(1 \mathrm{mmol})$, alkyne $(1.1 \mathrm{mmol})$ and catalyst $(20$ $\mathrm{mg}, 3.31 \mathrm{wt} \%, 0.0105 \mathrm{mmol}, 1.05 \mathrm{~mol} \%$ ) in $2 \mathrm{~mL}$ glycerol at room temperature. Yields were isolated yields.

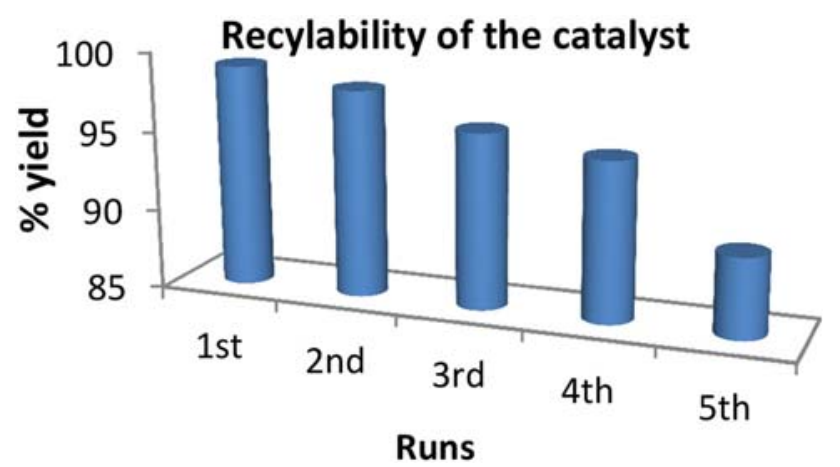

Figure 4. Recyclability of the catalyst.

nificant leaching of copper species from our catalyst during the recycling test which was confirmed by ICP analysis.

\section{Conclusions}

In conclusion, we have reported here a highly efficient and versatile method for the cycloaddition of various azides and alkynes using an easily prepared heterogeneous catalyst. Use of benign solvent, high yield, short reaction time, and room temperature reaction system make this protocol more advantageous in the synthesis of 1,4-disubstituted 1,2,3-triazoles. This work can be considered as a very good step towards the emerging trend of heterogeneous and environmental friendly synthesis of organic compounds.

\section{Supplementary Information (SI)}

General Information, Experimental and Analytical data, ${ }^{1} \mathrm{H}$ and ${ }^{13} \mathrm{C}$ NMR spectra and characterisation data of all the 
synthesised compounds are available as Supplementary Information at www.ias.ac.in/chemsci.

\section{Acknowledgements}

DS is thankful to CSIR, New Delhi, for a research grant [No. 02(0154)/13/EMR-II]. MC acknowledges UGC, New Delhi for UGC-BSR-RFSMS. Authors are also grateful to UGC, New Delhi for the Special Assistance Programme (UGCSAP) to the Department of Chemistry, Dibrugarh University and the Department of Science and Technology for financial assistance under the DST-FIST programme.

\section{References}

1. Billing J F and Nilsson U J 2005 C 2-symmetric macrocyclic carbohydrate/amino acid hybrids through copper(I)-catalyzed formation of 1, 2, 3-triazoles J. Org. Chem. 704847

2. Lober S, Raodriguez-Loaiza P and Geminer P 2003 Click Linker: Efficient and High-Yielding Synthesis of a New Family of SPOS Resins by 1,3-Dipolar Cycloaddition Org. Lett. 51753

3. Rengifo H R, Chen L, Grigoras C, Ju J and Koberstein J T 2008 "Click-Functional" Block Copolymers Provide Precise Surface Functionality via Spin Coating Langmuir 247450

4. Genin M J, Allwine D A, Anderson D J, Barbachyn M R, Emmert D E, Garmon S A, Graber D R, Grega K C, Hester J B, Hutchinson D K, Morris J, Reischer R J, Ford C W, Zurenko G E, Hamel J C, Schaadt R D, Stapert D and Yagi B H 2000 Substituent Effects on the Antibacterial Activity of Nitrogen-Carbon-Linked (Azolylphenyl)oxazolidinones with Expanded Activity Against the Fastidious Gram-Negative Organisms Haemophilus influenzae and Moraxella catarrhalis J. Med. Chem. 43953

5. Lee T, Cho M, Ko S Y, Youn H J, Baek D J, Cho W J, Kang C Y and Kim S 2007 Synthesis and Evaluation of 1,2,3Triazole Containing Analogues of the Immunostimulant $\alpha$-GalCer J. Med. Chem. 50585

6. Duan Y C, Ma Y C, Zhang E, Shi X J, Wang M M, Ye X W and Liu H M 2013 Design and synthesis of novel 1,2,3triazole-dithiocarbamate hybrids as potential anticancer agents Eur. J. Med. Chem. 6211

7. Palhagen S, Canger R, Henriksen O, Van Parys J A, Riviere M E and Karolchyk M A 2001 Rufinamide: A double-blind, placebo-controlled proof of principle trial in patients with epilepsy Epilepsy Res. 43115

8. Bakunov S A, Bakunova S M, Wenzler T, Ghebru M, Werbovetz K A, Brun R and Tidwell R R 2010 Synthesis and Antiprotozoal Activity of Cationic 1,4-Diphenyl$1 H$-1,2,3-Triazoles J. Med. Chem. 53254

9. Huisgen, R 1984 In1, 3-Dipolar Cycloaddition Chemistry A Padwa (Ed.) (New York: Wiley)

10. Rostovtsev V V, Green L G, Fokin V V and Sharpless K B 2002 A Stepwise Huisgen Cycloaddition Process: Copper(I)-Catalyzed Regioselective "Ligation" of Azides and Terminal Alkynes Angew. Chem. Int. Ed. 41 2596
11. Tornøe C W, Christensen C and Meldal M 2002 Peptidotriazoles on Solid Phase: [1,2,3]-Triazoles by Regiospecific Copper(I)-Catalyzed 1,3-Dipolar Cycloadditions of Terminal Alkynes to Azides J. Org. Chem. 673057

12. Moses J E and Moorhouse A D 2007 The growing applications of click chemistry Chem. Soc. Rev. 361249

13. Radatz C S, do Amaral Soares, L, Vieira E R, Alves D, Russowsky D and Schneider P H 2014 Recoverable $\mathrm{Cu} / \mathrm{SiO}_{2}$ composite-catalysed click synthesis of 1,2,3triazoles in water media New J. Chem. 381410

14. Lipshutz B H and Taft B R 2006 Heterogeneous Copperin-Charcoal-Catalyzed Click Chemistry Angew. Chem. Int. Ed. 458235

15. Raut D, Wankhede K, Vaidya V, Bhilare S, Darwatkar N, Deorukhkar A, Trivedi G and Salunkhe M 2009 Copper nanoparticles in ionic liquids: Recyclable and efficient catalytic system for 1,3-dipolar cycloaddition reaction Catal. Commun. 101240

16. Jin $\mathrm{T}$ N, Yan M, Bateer M, Minato T, Bao M and Yamamoto Y 2011 Nanoporous Copper Metal Catalyst in Click Chemistry: Nanoporosity-Dependent Activity without Supports and Bases Adv. Synth. Catal. 353 3095

17. Albadia J, Shiranb J A and Mansournezhad A 2014 Click synthesis of 1,4-disubstituted-1,2,3-triazoles catalysed by $\mathrm{CuO}-\mathrm{CeO}_{2}$ nanocomposite in the presence of amberlite-supported azide J. Chem. Sci. 126147

18. Zhang C, Huang B, Chen Y and Cui D M 2013 Porous copper catalyzed click reaction in water New J. Chem. 372606

19. Cintas P, Barge A, Tagliapietra S, Boffa L and Cravotto G 2010 Alkyne-azide click reaction catalyzed by metallic copper under ultrasound Nat. Protoc. 5607

20. French A D, Bertoniere N R, Brown R M, Chanzy H, Gray D, Hattori K and Glasser W 2004 InKirk-Othmer Encyclopedia of Chemical Technology $5^{\text {th }}$ edn. (New York: John Wiley) Vol. 5

21. Habibi Y, Lucia L A and Rojas O J 2010 Cellulose Nanocrystals: Chemistry, Self-Assembly, and Applications Chem. Rev. 1103479

22. Lahiji R R, Xu X, Reifenberger R, Raman A, Rudie A and Moon R J 2010 Atomic Force Microscopy Characterization of Cellulose Nanocrystals Langmuir 264480

23. Polshettiwar V and Varma R S 2010 Green chemistry by nano-catalysis Green Chem. 12743

24. Chavan P V, Pandit K S, Desai U V, Kulkarni M A and Wadgaonkar P P 2014 Cellulose supported cuprous iodide nanoparticles (Cell-CuI NPs): A new heterogeneous and recyclable catalyst for the one pot synthesis of 1,4-disubstituted - 1,2,3-triazoles in water $R S C A d v$. 442137

25. Ali A A, Chetia M, Saikia P J and Sarma D 2014 (DHQD) ${ }_{2}$ PHAL ligand-accelerated Cu-catalyzed azidealkyne cycloaddition reactions in water at room temperature $R S C A d v .464388$

26. Chetia M, Ali A A, Bhuyan D, Saikia L and Sarma D 2015 Magnetically recoverable chitosan-stabilised copper-iron oxide nanocomposite material as an efficient heterogeneous catalyst for azide-alkyne cycloaddition reactions New J. Chem. 395902

27. Ali A A, Chetia M, Saikia B, Saikia P J and Sarma D 2015 AgN $(\mathrm{CN})_{2} / \mathrm{DIPEA} / \mathrm{H}_{2} \mathrm{O}-\mathrm{EG}$ : a highly efficient 
catalytic system for synthesis of 1, 4-disubstituted-1, 2, 3 triazoles at room temperature Tetrahedron Lett. 565892

28. Ali A A, Chetia M and Sarma D 2016 Urea assisted copper(I)-catalyzed azide-alkyne cycloaddition reactions in water Tetrahedron Lett. 571711

29. Konwar M, Ali A A, Chetia M, Saikia P J and Sarma D 2016 Fehling solution/DIPEA/hydrazine: An alternative catalytic medium for regioselective synthesis of 1,4-disubstituted-1 $H$-1,2,3-triazoles using azide-alkyne cycloaddition reaction Tetrahedron Lett. 574473

30. Ali A A, Konwar M, Chetia M and Sarma D 2016 [Bmim] OH mediated $\mathrm{Cu}$-catalyzed azide-alkyne cycloaddition reaction: A potential green route to 1,4disubstituted 1,2,3-triazoles Tetrahedron Lett. 575661
31. Konwar M, Ali A A, Chetia M, Saikia P J, Khupse N D and Sarma D 2016 ESP Promoted "On Water" Click Reaction: A Highly Economic and Sustainable Protocol for 1,4-Disubstituted-1 $H$-1,2,3-Triazole Synthesis at Room Temperature ChemistrySelect 16016

32. Mora'n J I, Alvarez V A, Cyras V P and Va'zquez A 2008 Extraction of cellulose and preparation of nanocellulose from sisal fibers Cellulose 15149

33. Hu Y, Tang L, Lu Q, Wang S, Chen X and Huang B 2014 Preparation of cellulose nanocrystals and carboxylated cellulose nanocrystals from borer powder of bamboo Cellulose 211611 